This is an electronic reprint of the original article. This reprint may differ from the original in pagination and typographic detail.

Author(s): Zhang, Boyang; Vos, Marita; Veijalainen, Jari

Title: Decomposing issue patterns in crisis communication : the case of the lost airliner

Year: $\quad 2018$

Version:

Please cite the original version:

Zhang, B., Vos, M., \& Veijalainen, J. (2018). Decomposing issue patterns in crisis communication : the case of the lost airliner. International Journal of Emergency Management, 14(1), 72-89. https://doi.org/10.1504/IJEM.2018.10010176

All material supplied via JYX is protected by copyright and other intellectual property rights, and duplication or sale of all or part of any of the repository collections is not permitted, except that material may be duplicated by you for your research use or educational purposes in electronic or print form. You must obtain permission for any other use. Electronic or print copies may not be offered, whether for sale or otherwise to anyone who is not an authorised user. 
Zhang, B., Vos, M. \& Veijalainen, J. (2018), Decomposing issue patterns in crisis communication - The case of the lost airliner. International Journal of Emergency Management, Vol. 14, No. 1, pp. 72-89.

\title{
Decomposing issue patterns in crisis communication - the case of the lost airliner
}

\author{
Boyang Zhang \\ Department of Computer Science and Information Systems \\ University of Jyvaskyla, Finland \\ Email: boyang.zhang@jyu.fi \\ Marita Vos* \\ Corporate Communication JSBE \\ University of Jyvaskyla, Finland \\ Email: marita.vos@jyu.fi \\ *Corresponding author \\ Jari Veijalainen \\ Department of Computer Science and Information Systems \\ University of Jyvaskyla, Finland \\ Email: jari.veijalainen@jyu.fi
}

\begin{abstract}
This research explores the relation between a crisis and public discussion on related issues. In organisational crisis communication, a singleissue strategy is often proposed. Such a strategy, however, may not be adequate in more complex crises where the crisis lifecycle is likely to encompass shorter lifecycles of issues that generate media attention. Decomposing the online crisis debate into a pattern of issues supports understanding of public perceptions, and hence of crisis response and communication. This is investigated through an analysis of Facebook posts prompted by the loss of Malaysia Airlines flight MH370 in 2014. The analysis shows that during the life of the crisis a variety of related issues arose that became topics of public debate. Compassion for victims dominated in the early stages of the crisis, while later on reputation-related issues took over. The insights gained help in understanding the results of social media monitoring during complex organisational crises and facilitate organisational decision making.
\end{abstract}

Keywords: crisis communication; organisational communication; issue arenas; issues management; social media. 
Zhang, B., Vos, M. and Veijalainen (in press, 2017), Decomposing issue patterns in crisis communication - The case of the lost airliner. Emergency Management, Vol. 13.

Biographical notes: Boyang Zhang is a Doctoral Researcher of the University of Jyvaskyla, Finland. His research interests include company communication and, in particular, social media interaction. In his research, he combines insights in corporate communication and information technology.

Marita Vos, $\mathrm{PhD}$, is a Professor of Organizational Communication and $\mathrm{PR}$ at the University of Jyvaskyla, Finland. She led several EU-funded projects in the security area, see www.crisiscommunication.fi. Her research centres on multiactor networks in turbulent environments, including crises and societal issue arenas.

Jari Veijalainen, $\mathrm{PhD}$, is a Professor of Software Engineering at the University of Jyvaskyla, Finland. His research focuses on heterogeneous transaction management, transaction models and mechanisms for computer supported cooperative work, workflow systems and electronic commerce systems, formal modelling, mobile computing, software engineering, mobile multimedia data management, and social media analysis.

This paper is a revised and expanded version of a paper entitled 'Evolving crises bring multiple issues in social media' presented at NordMedia, Copenhagen, 14 August 2015.

\section{Introduction}

To better understand public perception and needs during a crisis, media content is monitored. Monitoring interaction in the social media reveals what topics are discussed and where, and how often this is the case. Facebook data, for example, can enable the construction of frequency graphs. Topics of general concern need attention in crisis communication. This paper focuses on decomposing issue patterns in times of crisis. Understanding how issues evolve during a crisis may help decision making on communication strategies with diverse public groups. It is reasonable to assume that during the lifecycle of a crisis, various related issues with shorter lifecycles will also arise and be discussed, in which case insight into such patterns may help understand the crisis-related discourse proper and enhance organisational crisis communication with public groups.

In the literature on organisational crisis communication, single-issue strategies, such as apologia, are often discussed. The situation is different in issues management, where the tracking of multiple issues is recommended, even if these issues do not usually coincide time. Online communication gives opportunities to track multipleissues related to a particular organisational crisis, and so better understand the online discourse.

Such communication insights and skills are not needed solely by public organisations; private sector transport and energy companies, for example, may also need to interact with stakeholders affected by a crisis. The aim of this study is to better understand the issue patterns that emerge during the lifetime of an organisational crisis. By defining a crisis as an accumulation of crisis-related issues, this paper also invites 
Zhang, B., Vos, M. and Veijalainen, J. (in press, 2017), Decomposing issue patterns in crisis communication - The case of the lost airliner. Emergency Management, Vol.13.

a more theoretical discussion, including exploring how crisis communication theory may be strengthened by connecting it with insights on communication about issues. In this study, attention is also given to social media, as in the online environment issues may travel fast, possibly causing crises to expand. In this section, we first introduce the topic of crises and evolving issues over time, and then discuss the spread of issues in social media.

\subsection{Crisis communication debate}

Crises are situations of high uncertainty that take organisations and people by surprise and call for a response to mitigate threats and reduce harmful consequences (Stephens et al., 2005; Ulmer et al., 2007). The discourse in crisis times has been characterized as multi-actor interaction (Gutteling, 2001), taking place in a rhetorical arena (Heath and O'Hair, 2009; Frandsen and Johansen, 2010). Therefore, crisis communication forms a complex combination of various actors, contexts and discourses (Frandsen and Johansen, 2010). Crisis debate includes discussions of exchange and has rhetorical dynamics, as different views and interests may show over time (Heath and O'Hair, 2009).

According to Jaques (2009), scholars' views on how to describe a crisis differ; some define a crisis as an extreme event and others see it as part of a more prolonged process. Recently, the latter view has gained ground. For example, a process model of the lifecycle of a crisis has been proposed by Coombs (2001), who describes three consecutive phases, starting from the detection of the pre-crisis signal: prevention and preparation, recognition and containment of the crisis event, and the post-crisis phase, including evaluation, learning and follow up. Similarly, the CERC model (Reynolds and Seeger, 2005; Veil et al., 2008) proposes five phases with corresponding communication tasks throughout the crisis lifecycle. The various communication tasks have also been developed into an audit for crisis communication (Palttala and Vos, 2012).

In a crisis situation, public expectations towards an organisation may not be met, even to the extent that relationships may be challenged (Heath and Palenchar, 2009). In the literature on organisational crises, therefore, the importance of (re)gaining trust and ensuring the reliability of information is underlined (e.g. Hiltz et al., 2011; Hyvärinen et al., 2015). This has led to theory development on apologia, where an organisation clarifies its role in relation to how the crisis came about. For example, it may apologize for causing or adding to the crisis, or deny any responsibility for it (e.g. Benoit, 1995; Coombs, 2012). The emphasis is then on one main issue, i.e., what has led to the crisis situation as perceived from the organisational point of view. Such crises may be of relatively short duration or the interest is centred on the initial stage of the outbreak of the crisis. However, companies also face longer and more complex crises for which a single-issue strategy may not be adequate as new issues related to the crisis may come up over time that require different strategies. In any case strategies can be combined, for example, compassion communication strategies could be added to apologia response strategies (Romenti and Valentini, 2010).

Moreover, the manageability of crises has been debated, and flexibility is nowadays also deemed important in dealing successfully with the evolving situation (Falkheimer and Heide, 2010). Changes over time in the perspectives used in news media were, for 
Zhang, B., Vos, M. and Veijalainen (in press, 2017), Decomposing issue patterns in crisis communication - The case of the lost airliner. Emergency Management, Vol. 13.

example, reported after explosions at a fireworks factory (Kuttschreuter and Gutteling, 2009). This indicates that a complex crisis situation, along with the crisis discourse accompanying it, may change over time, giving rise to public debate on different crisisrelated issues.

\subsection{Issues management}

Through issues management, organisations keep track of evolving issues that have the potential to turn into an organisational crisis and, consequently, have an impact on their operations (Heath and Nelson, 1986). Therefore, issues management can be seen as an early warning system of a potential crisis. Issues are controversial topics in the public debate (Vos and Schoemaker, 2011). A problem becomes an issue when a private concern is voiced in public (Coombs, 2002) and many individuals discuss a similar concern with others (Hallahan, 2001). An issue may be debated over a longer or shorter time span. Some issues attract attention for a relatively short period of time, while other issues receive a high level of attention for a prolonged period. According to the "issue-attention cycle" theory posited by Downs (1972), an issue can only capture public attention for a limited period of time, usually from a few days up to a few weeks. If it receives attention, the level of that attention over time may grow and further continue to expand before levelling off and fading away (Vos and Schoemaker, 2011). Hence, issues are commonly described as having a lifecycle comprising five stages - potential, emerging, current, crisis and dormant (Regester and Larkin, 2008).

Issues management aims at either promoting favourable trends or adjusting to expectations in the social environment in order to enhance relationships (Heath, 1998; Heath, 2002). In this way, by achieving fuller understanding of the formation of public policy, issues management has come to exert a profound influence on the performance of organisations (Crable and Vibbert, 1985).

Researchers have rarely reached a consensus on the question of how issues management and crisis communication are related. The studies carried out by Jaques $(2009$, p. 285) revealed that the two are not always linked, as "issues management may be structurally positioned primarily as a communication role within the public relations function" whereas "crisis management may be structurally positioned alongside security and emergency response and assigned to operational managers and technicians; or within the CEO's staff and aligned with strategic planning". However, in this study we assume that insights into communication on issues can also be valuable in crisis situations. The preventive function of issues management, in the phase before a crisis erupts, has been emphasized in the literature (e.g. Gonzalez-Herrero and Smith, 2008); however, we would argue that issues management is needed also during crises.

Although not all issues will be related to a crisis situation, some issues may grow and develop into a reputation crisis for an organisation. Much attention is given in the literature to ways of managing issues to prevent the occurrence of such reputation crises or reduce reputation damage (e.g. Coombs, 2007). This includes building stakeholder relations well before a crisis occurs, and arranging a process of multi-actor interaction concerning risks instead of just providing top-down information to stakeholders (Gutteling, 2001).

In this paper, the focus is not on reputation crises per se, but rather on complex emergency situations that, while they may also affect organisational reputations, 
Zhang, B., Vos, M. and Veijalainen, J. (in press, 2017), Decomposing issue patterns in crisis communication - The case of the lost airliner. Emergency Management, Vol.13.

primarily affect public groups: for example, an accident leading to a crisis situation that may affect various stakeholder groups. Throughout such a complex crisis, different issues may be discussed in the public arena, possibly adding to the severity of the crisis.

A proactive approach to crisis management has been proposed (Coombs, 1992). This approach underlines the importance of monitoring activities in the traditional and virtual media (Zhang and Vos, 2014). Nowadays, next to monitoring, interaction itself has also been emphasized; rather than merely observing and deciding whether to act or not, it is considered important to stay in touch with public groups on a continuous basis. The inclusion of social media in particular, in monitoring activities, which are performed remotely over the internet, is nowadays considered an inevitable trend (Heath and Palenchar, 2009). Semenov and Veijalainen (2013) have recently developed a modelling framework as a basis for social media monitoring to capture longitudinal network online development. At the same time, several researchers have demonstrated the heavy impact of emotions on discourse concerning issues and crises (e.g. Bronstein, 2013; Liu and Kim, 2011; Stieglitz and Dang-Xuan, 2013). Consequently, when monitoring media content, it is important that, next to information, emotions are taken into account. By using online monitoring techniques, we attempt to enhance understanding of the discourse that occurs in the case of complex organisational crises. In particular, online monitoring offers possibilities to decompose issue patterns to better understand this discourse and support strategy decisions.

\subsection{Understanding issue spread in the social media}

Social media discourse in emergency situations is co-created by citizens, response organisations and others. The intention, personality and motives of individual users drive their behaviour in social media (Anderson, 2011; Wang, 2012; Wybo et al., 2015). Being an eyewitness of a crisis event has considerable potential to engage people in interaction via social media (Zhang and Vos, 2014). Such messages may spread widely, especially via Twitter, which lacks gatekeeping and can thus disseminate issues rapidly via its large user base (Hughes and Palen, 2009; Pang et al., 2014). 'Twitter Journalism' also seems to offer the stamp of public approval when accompanied with live images (Tam, 2012), for which reason news media monitor Twitter for confirmation of breaking news (Terdiman, 2014). Other motives for engaging in social media during crisis events are seeking information or assistance, but also telling others that one is okay, sharing grief and emotional support, expressing criticisms and co-creating solutions.

As the trend towards the usage of social or real-time media strengthens, it also adds to the speed with which crisis events develop. Consequently, understanding the way in which information spreads in the online environment is important in crisis situations (Zhang and Vos, 2015). Cascading refers to a message being passed to a first group of receivers who in turn pass it on to the next, igniting further explosions of information. Simple cascading has been contested in studies that have pointed to the existence of thresholds and have suggested that the widening diffusion of information would be better explained as triggered by a collision of shorter chains of communication (Rogers et al., 2012). This line of thinking has also led to studies investigating the role of weak 
Zhang, B., Vos, M. and Veijalainen (in press, 2017), Decomposing issue patterns in crisis communication - The case of the lost airliner. Emergency Management, Vol. 13.

links in passing messages on to other groups of users (Zhao et al., 2010). The concept of viral spreading suggests that online diffusion can be compared to the spread of a contagious disease, and has led to studying the 'infection time' of users in social media. It has been suggested that influential users, for example popular bloggers, can facilitate the process through which messages go viral. How often a message is passed on over time has been shown in frequency graphs, in line with the diffusion of innovation theory proposed by Rogers (1995). The diffusion of online messages is assumed to die out after a while. Similarly, issues that are discussed online are also expected, after showing growth, to decay at some point. Put differently, different issues arise and compete for attention, some becoming hot topics while others quickly fade. To be able to deal with an evolving crisis situation, the results of monitoring need to support understanding of complex issue patterns.

\section{Pre-study}

The idea of decomposing issue patterns was derived from a pre-study into the older case of the leak in the nuclear reactor owned by the Tokyo Electric Power Company (TEPCO) in Fukushima in 2011. On March 11, 2011, an earthquake occurred near the Sanriku coast of Japan, triggering a tsunami with waves up to 10 meters high. This had an impact, in particular, on TEPCO's Dai-ichi Nuclear Power Plant. During the earthquake, landlines and mobiles were out of operation (Jung 2012), leaving social media the least congested channel of communication. Therefore, social media interactions were frequent.

The pre-study was conducted to clarify if the selected approach to researching issues throughout a crisis would reveal any interesting patterns. As this was done postcrisis, sources could be used that looked back on the TEPCO Fukushima crisis, and hence a secondary analysis of peer-reviewed articles was the method of choice, to test the approach of decomposing issues evolving during a crisis. We wanted to identify the issues discussed and how their discussion evolved over time during the crisis.

First, articles were gathered from peer-reviewed scientific journals, using Meta search via the ProQuest and the EBSCO host databases, applying the keywords (communication OR "social media") AND (crisis OR disaster) AND (Fukushima OR TEPCO). The search spanned the period from the outbreak of the Fukushima crisis in 2011 to its end in 2015. As a first step, duplicates were discarded and the abstracts and titles of 121 articles were checked for relevance according to the keywords; most of the articles, however, were about health and physics. After this initial scan, 35 articles were copied to RefWorks software for further analysis. After reading the articles, 11 were selected as relevant for this study, as they mentioned communication with or by the public, and. Application of snowballing techniques yielded 4 more relevant articles. Thus the final sample comprised 15 articles, published during the years 20112015. A secondary thematic analysis, using a data-extraction table with the sources as rows and themes as columns, was used to identify the different issues discussed over time according to the articles.

The analysis showed that various themes were discussed in the public debate following the radioactive leakage. The results yielded four themes: understanding of the event, reliability of information, personal safety, and the future of nuclear energy. 
Zhang, B., Vos, M. and Veijalainen, J. (in press, 2017), Decomposing issue patterns in crisis communication - The case of the lost airliner. Emergency Management, Vol.13.

The first theme found was understanding of the event. According to the academic sources, initially, after the tsunami, the lack of information caused much speculation. Bloggers misinterpreted the available information, and the social media discussion included inaccuracies and mistakes (Pierpoint, 2011; Ionescu, 2012). Alarming information was also proliferating in Twitter (Li et al., 2014). People did not fully understand what had happened or what impact it would have for them personally (Jung, 2012). Many researchers concluded that the news of the meltdown had a devastating impact (Li et al., 2014; Ng and Lean, 2012; Pierpoint, 2011; Utz et al., 2013), generating widespread fear among the public in the absence of accurate authorized information.

The second theme was the reliability of information. After the incident, the Japanese government sought to calm the public (Utz et al., 2013). However, the international news media reported that withholding information made it difficult to accurately report radiation levels, and people questioned whether the government was telling the truth or covering up potential risks (Li et al., 2014). TEPCO was blamed for the lack of preventive action, and the news media reported resignations of its top executives in 2002 following earlier reports of the falsifying of safety records (Cotton et al., 2015). In the present instance, the high radiation levels mentioned in the media were for the most part denied by TEPCO (Pierpoint, 2011), which further fed public anxiety (Cotton et al., 2015). People turned to other sources, such as their networks of friends and the media (Robertson and Pengilley, 2012). Many local news media set up social media accounts to broadcast information (Jung, 2012), and a YouTube video in which a Japanese nuclear expert who criticized the inaccuracy of the available information went viral ( $\mathrm{Ng}$ and Lean, 2012).

The third theme was personal safety. Many authors indicated that people tried to gather information on the potential risks to food, water and air, and what behaviour could prevent or minimize risks (Frank and Schvaneveldt, 2014; Robertson and Pengilley, 2012; Wang et al., 2013). TEPCO provided little information to the public but left this to the government, which in turn was reliant upon TEPCO for this very information (Cotton et al., 2015). With incomplete understanding of the situation and possible actions to control the threat to their safety (Robertson and Pengilley, 2012), many people became highly alarmed (Frank and Schvaneveldt, 2014). In addition, citizens far removed from the disaster began to worry more about possible health impacts than the situation warranted ( $\mathrm{Ng}$ and Lean, 2012; Pierpoint, 2011); for example, people living in Europe bought iodine unnecessarily.

The fourth theme was the future of nuclear energy. Some scholars noted that for many people nuclear contamination was an incomprehensible and unfamiliar issue (Wang et al., 2013). The future of nuclear energy came to be hotly debated after the incident, in particular in relation to terrorism risks and lack of governance (Goudarzi et al., 2015; Ionescu, 2012).

Next, we looked into the debate as it evolved. One source provided insight in the total number of tweets over time. Li et al. (2014) concluded that, at the beginning of the crisis, fear of meltdown was the main topic discussed on Twitter. This particular issue peaked at 38,300 retweets at the end of March 2011. The authors provided a figure charting the total number of retweets in the first weeks after the tsunami, and described some of the trends in the topics discussed, such as that, especially at the beginning of the crisis, uncertainties and concerns were voiced. Other sources added 
Zhang, B., Vos, M. and Veijalainen (in press, 2017), Decomposing issue patterns in crisis communication - The case of the lost airliner. Emergency Management, Vol. 13.

insights on how issues changed over time. For example, by the end of March attention began to shift to issues related to the response to the crisis and the implications of the crisis for food safety (Wang et al., 2013), while the future of nuclear energy was mostly debated later on, in April 2011 (Jung 2012).

In addition, we checked both the government's and TEPCO's accounts. We noted that although the Japanese prime minister's office set up a Twitter account in March 2011, no tweets were sent out that year. TEPCO established a verified Japanese Twitter profile@OfficialTEPCO on March 17, 2011, another verified Japanese profile @TEPCO_Nuclear in May 2011, and an English verified profile @TEPCO_English on May 30, 2011. One can argue that the above profiles were established because of the disaster on March 11, but at the same time it is clear that none of them was actually used during the first days of the crisis. The profile @TEPCO_Nuclear was established to disseminate information about the Fukushima disaster. The description of this active profile mentions apologies for the inconvenience and worries caused to Japanese society by TEPCO. We were able to collect all the tweets from the English profile, although it did not begin to be used until June 2, 2011. The tweets were mostly about the current power distribution status, and hardly touched on the Fukushima accident.

The pre-study showed that although a precise decomposition of issues was not given, it was clear that a combination of issues was present throughout the TEPCO Fukushima crisis. It seems that uncertainties and public concerns were met with apologies and efforts to calm the population, while the credibility of the information released was questioned, adding further to the criticism levelled at the government and TEPCO. The online environment was not prioritised by the Japanese government, which instead relied primarily on news media relations, whereas TEPCO, which had an active Japanese Twitter account, only began to use the account in English late into the crisis and for a different purpose, possibly underestimating international concerns about the crisis and the future of nuclear energy. After this pre-study, conducted to gain a clearer insight into issue patterns during a crisis, we selected a more recent case to empirically investigate crisis-related issue discourse online. Below we outline the methodology used to decompose issue-spread patterns during an organisational crisis, describe the outcomes of the subsequent empirical study, and present conclusions.

\section{Methodology}

The aim of this empirical study is to better understand the issue patterns that manifest in the online environment during the lifecycle of a specific organisational crisis, as this may support decision making on communication strategies. The research questions are: (RQ1) What crisis-related issues are discussed online during the crisis? (RQ2) How do these issues evolve during the crisis?

Issue patterns found may clarify how the debate evolves over time. A timeline analysis has been conducted in earlier studies, for example, revealing interesting results concerning evolving news media discourse (Kuttschreuter and Gutteling, 2009). Here we study similar changes over time, focusing on social media content as suggested earlier, for example, by Nijkrake et al. (2015).

This study, which was conducted during and after the crisis, focuses on the loss of Malaysia Airlines flight MH370 in March 2014. Issues were extracted to clarify the 
Zhang, B., Vos, M. and Veijalainen, J. (in press, 2017), Decomposing issue patterns in crisis communication - The case of the lost airliner. Emergency Management, Vol.13.

public debate on the lost airliner. The data included real-time media content, in particular, interaction on the official Facebook discussion platform of Malaysia Airlines.

First, to gain acquaintance with the case, some Twitter data were collected using topsy.com, a platform for social media analytics. The key word was the flight number "MH370". The period sampled ran from March 5 to April 10, 2014. The total number of tweets found on the topic was 4,287,228. Next, a frequency graph was constructed from the collected data, to provide a first overview of the evolving online discussion.

To view the discourse in greater detail, an inventory of related Facebook platforms was created by searching in Facebook for the keywords Malaysia Airlines. Three main homepages were scrutinised. Malaysia Airlines' official discussion platform was selected for the investigation, as it was dedicated to the issue of the lost airliner and almost wholly comprised citizen reactions

(www.facebook.com/malaysiaairlines). Malaysia Airlines posted 12 posts with news updates, while all the other posts were from citizens. The company did not comment on or reply to citizens' posts, but allowed citizens to comment on each other's posts. It may, however, have monitored public concerns so as to respond to them via other social or news media.

The sample period ran from March 7 to March 27, 2014. All posts in English and Chinese, which together accounted for $96.5 \%$ of all the posts visible on the platform, were included. The posts were copied into the research database, checked for anonymisation, and kept on a password-protected server. The thematic analysis was conducted by applying ATLAS.ti 7. After an initial reading of the content, all the posts, each consisting of 1 to 3 sentences, were carefully re-read. Some posts had been placed as a comment connected to other posts, but as these were often not related in their content, the analysis focused on posts as individual posts only and not as strings of posts.

In cases of literal repetition by a user across several posts, only the first was coded. In total, 3120 posts were coded. Every comment was coded into one of the following six family groups of codes: concern for victims, discussion on the causes, safety of flying, reputation, speculation on the location of the airliner, and other. Within each group of codes, the posts were further analysed by marking keywords. Using Atlas.ti software and SPSS, more insight was gained into which keywords appeared most often and whether they showed any inter-correlations. This helped summarize the content of the posts within each family of codes, reducing them to one issue each. This was done to gain insight into the issues discussed. Finally, we compared the numbers of posts per family code, i.e., per issue, over time. For this purpose, a frequency graph was constructed from the collected data to track how the issues developed over time and whether multiple shorter issue life cycles manifested within the lifecycle of the crisis.

\section{Findings}

On March 7, 2014, Malaysia Airlines reported that a Boeing 777-200 had lost contact with the control centre. The airliner, flight number MH370, had departed from Kuala Lumpur with Beijing as the planned destination. It should have arrived in Beijing at 
Zhang, B., Vos, M. and Veijalainen (in press, 2017), Decomposing issue patterns in crisis communication - The case of the lost airliner. Emergency Management, Vol. 13.

6:30 am local time on March 8, 2014 (UTC 22:30 March 7, 2014). After air traffic control reported losing contact with the airliner, Malaysia Airlines immediately operationalized their rescue mechanism to locate its position (UTC 17:40 March 7, 2014). The lost airliner had 239 people from 14 countries on board, 227 of whom were passengers and $12 \mathrm{crew}$ members. The reason for loss of contact with the control centre was under investigation, and, with joint efforts involving many countries, the search and rescue operation began.

On March 24, 2014 Malaysia Airlines announced that the airliner had crashed in the southern Indian Ocean, west of Perth, Australia. On March 8, 2015, one year after the Malaysian Government had announced that an international panel would investigate the MH370 crash, an interim report of 584 pages was released by the Malaysian Ministry of Transport. It was written in airline industry jargon and raised yet more doubts, while the specific location of the plane remained unknown. Next, we report the analysis of the data.

\subsection{Analysis of Twitter data}

First, we present a frequency graph of the online discourse and then elaborate on the development of the debate over time. The Twitter data consist of top tweets, used to gain familiarity with the case, whereas the later Facebook data were analysed in greater depth. Several themes relating to the missing airliner were present in the top tweets, including uncertainty and grief over the victims, and speculation on the cause and location of the airliner.

Next, we traced the development of issues on Twitter over time. Using the Twitter data, a frequency graph was constructed to show the distribution of tweets over time (see Figure 1).

\section{Tweets}

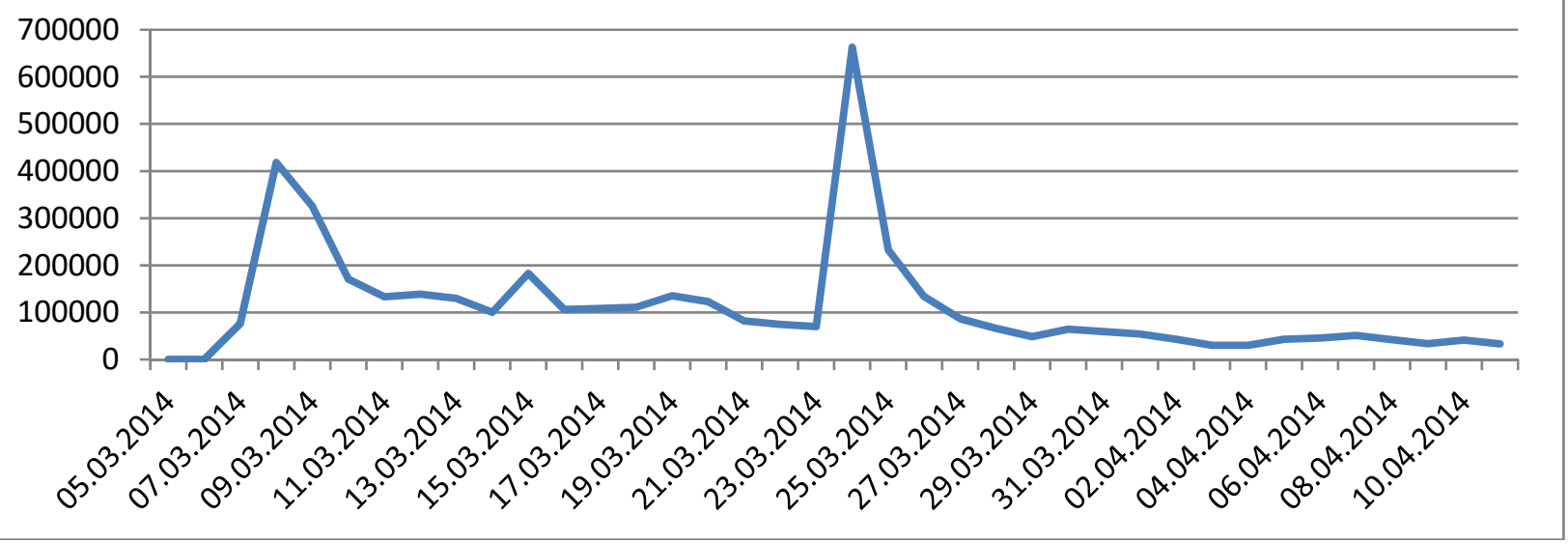

Figure 1 Frequency graph of Twitter messages on the lost airliner

Figure 1 shows the number of tweets containing the word "MH370" from the beginning of March to the end of April. Two high peaks are visible. The first peak, of 
Zhang, B., Vos, M. and Veijalainen, J. (in press, 2017), Decomposing issue patterns in crisis communication - The case of the lost airliner. Emergency Management, Vol.13.

418,008 tweets, occurred on March 8, just after the news had broken. There was much speculation about what had happened to the airliner, including a possible terrorist attack. Thereafter, the number of tweets varied somewhat, although largely remaining around 100,000 until March 23, when the number rose sharply for the second time, peaking at 662,759 . This was at the point when it became known that the airliner had crashed. The next day, the number of tweets began to decline steadily, levelling off after March 29 at the level of approximately 50,000 per day.

The frequency of the tweets shows a pattern of two sharp peaks. One or more sharp peaks are typical in the case of crisis situations, as these are emotional and disturbing events that quickly generate a large volume of social media interaction. The relatively high levels of tweets following the two peaks may be explained by the fact that the situation remained unresolved. The crisis incident clearly attracted much international attention.

\subsubsection{Uncertainty and grief over the victims}

On March 8, 2014 (MYT Malaysia Time, 8 hours ahead of UTC), Malaysia Airlines announced via the news media that contact had been lost with flight MH370. This resulted in expressions of uncertainty and grief in social media. On March 7 (UTC), the top tweet (79,184 tweets) was: “@yahoo: RT@ABC: Image from @flightaware shows last known track of Flight MH370 over southern Asia”. The next day's top tweet (418,008)“@hayano: Malaysia Airlines 'still unable to establish any contact or determine the whereabouts of flight MH370',', was almost six-fold higher. On March 9 the top tweet, “@detikcom: Kerabat Penumpang MH370 di China: Teleponnya Hidup Namun Tak ada Jawaban” (MH370 passengers in China: the telephone live, still no answer), had dropped slightly to 325,390 .

After the announcement about missing flight MH370, two peaks occur. The first, already referred to above, is on March 8, 014. The second is on March 24, 2014 “@yahoo: Malaysian Prime Minister Najib Razak vows 'We will not rest' until the fate of Flight MH370 is known"”. The Twitter data reflect the uncertainties characterizing the incident.

\subsubsection{Speculations on the cause and location}

Twitter was full of rumours and guesses about the missing plane. There were speculations on the reasons why the plane had deviated from the flight plan, whether the plane had been high jacked, and, if so, whether this related to terrorism or not: for example, on March 12, 2014 “@yahoo: Malaysia Airlines Flight MH370 pilot’s last recorded words do not indicate any danger: http://t.co/y2uezxsquK 'All right, good night'”.

The possible location of the airliner was also debated, as in this tweet on March 14 ${ }^{\text {th }}$,2014, “@abc: US official to @ABC: Flight MH370 search in Indian Ocean to focus on 2 probable paths: http://t.co/DnuM8AZDkY - @LMartinezABC”. On March 24,2014 , another peak, of about 662,759 tweets, is visible in the frequency graph, for the tweet “@piersmorgan: 'It is with deep sadness and regret that new data (indicate) flight MH370 ended in the Southern Indian Ocean' - Malaysia Prime Minister'”. According to a report by the British Aviation Accident Investigation Branch, the 
Zhang, B., Vos, M. and Veijalainen (in press, 2017), Decomposing issue patterns in crisis communication - The case of the lost airliner. Emergency Management, Vol. 13.

Malaysian prime minister had announced in a press conference that, based on the southern route of the flight, the plane's last position was most likely in the Southern Indian Ocean. This was heavily discussed on Twitter, as in this tweet on March 28, 2014 “@breakingnews: Australia says plane spots objects in MH370 search area; ship confirmation not expected until tomorrow - @AMSA_News, @Reuters”. The news remained unconfirmed.

As in the Fukushima case, in the days following the missing plane crisis the public was expressing sympathy and concern, and trying to learn what exactly had happened. Analysis of the content of the top tweets showed many emotions, e.g. from compassion to anger, worries about whether flying was still safe, and speculation about why the plane had deviated from its route and finally crashed. In order to gain a deeper insight into the contents of the discourse, the posts on the Facebook platform were investigated.

\subsection{Analysis of issues mentioned on the Facebook platform}

To look in more detail at the themes discussed on line and their development over time, the official Facebook discussion platform of Malaysia Airlines (www. facebook.com/malaysiaairlines) was analysed. The total number of posts on the Facebook platform from March 7 to 27, 2014 was 3,718. The content of the posts showed six major themes: these were concern for victims (1,922 posts), possible causes (711 posts), speculation on the location of the airliner (432 posts), the company's reputation (255 posts), the safety of flying ( 74 posts) and other (324 posts). We will first describe the themes discussed on the official Facebook platform of Malaysia Airlines and then show their development over time.

\subsubsection{Concern for victims}

During the crisis, many social media posts expressed grief and offered up prayers in a gesture of unprecedented solidarity towards the missing passengers. The largest number of coded messages were clustered around this theme. The posts manifest emotional responses, such as sadness, anger, distress.

\subsubsection{Possible causes}

The lack of information on the possible cause led to the spread of rumours and conspiracy theories. People discussed, for example, whether the pilot had hijacked the airliner and whether there may have been terrorist motives, whether two passengers had fake passports, or whether there may have been technical problems.

\subsubsection{Speculation on the location of the airliner}

The theme of speculation on the location of the airliner shows similar peaks as those on the theme of concern for the passengers, although the numbers of posts are considerably smaller. Posts on this theme include how to locate the plane and possible 
Zhang, B., Vos, M. and Veijalainen, J. (in press, 2017), Decomposing issue patterns in crisis communication - The case of the lost airliner. Emergency Management, Vol.13.

techniques for doing so, guesses at the plane's location, mentioning places as far apart as Australia, China, Vietnam, Malaysia, and so on.

\subsubsection{Company reputation}

Coded under this theme were posts questioning the reliability and credibility of the official announcement stating that the airliner had crashed in the southern Indian Ocean. Although historically other planes have been lost, this was hard to accept. Many asked for proof confirming the announcement, while others attributed responsibility for possible faults to Malaysian Airlines. People wondered whether the company's safety measures had been strict enough, and if action should have been taken on earlier signs of dubious behaviour on the part of the pilot. They questioned whether the company's communications had been inadequate or whether the response had been slow.

\subsubsection{Safety of flying}

Some people discussed whether it was safe to fly. The numbers of messages coded under this heading were low, although flight bookings fell, particularly for this airline, and even further after another airliner operated by Malaysia Airlines crashed in the Ukraine war zone in July 18, 2014.

\subsubsection{Other}

The messages on the platform coded as 'Other' were diverse and often not relevant to the incident.

\subsection{The development of issues on the Facebook platform over time}

To analyse the development of issues over time, a frequency graph was drawn using data gathered from the official Facebook chat platform of Malaysia Airlines (see Figure 2). The graph shows four lines, one for each code. The codes 'Safety of flying' and 'Other' are not included in this figure, as the maximum number of posts per day on 'Safety of flying' was less than 20, and the code 'Other' mostly contained irrelevant information. 
Zhang, B., Vos, M. and Veijalainen (in press, 2017), Decomposing issue patterns in crisis communication - The case of the lost airliner. Emergency Management, Vol. 13.

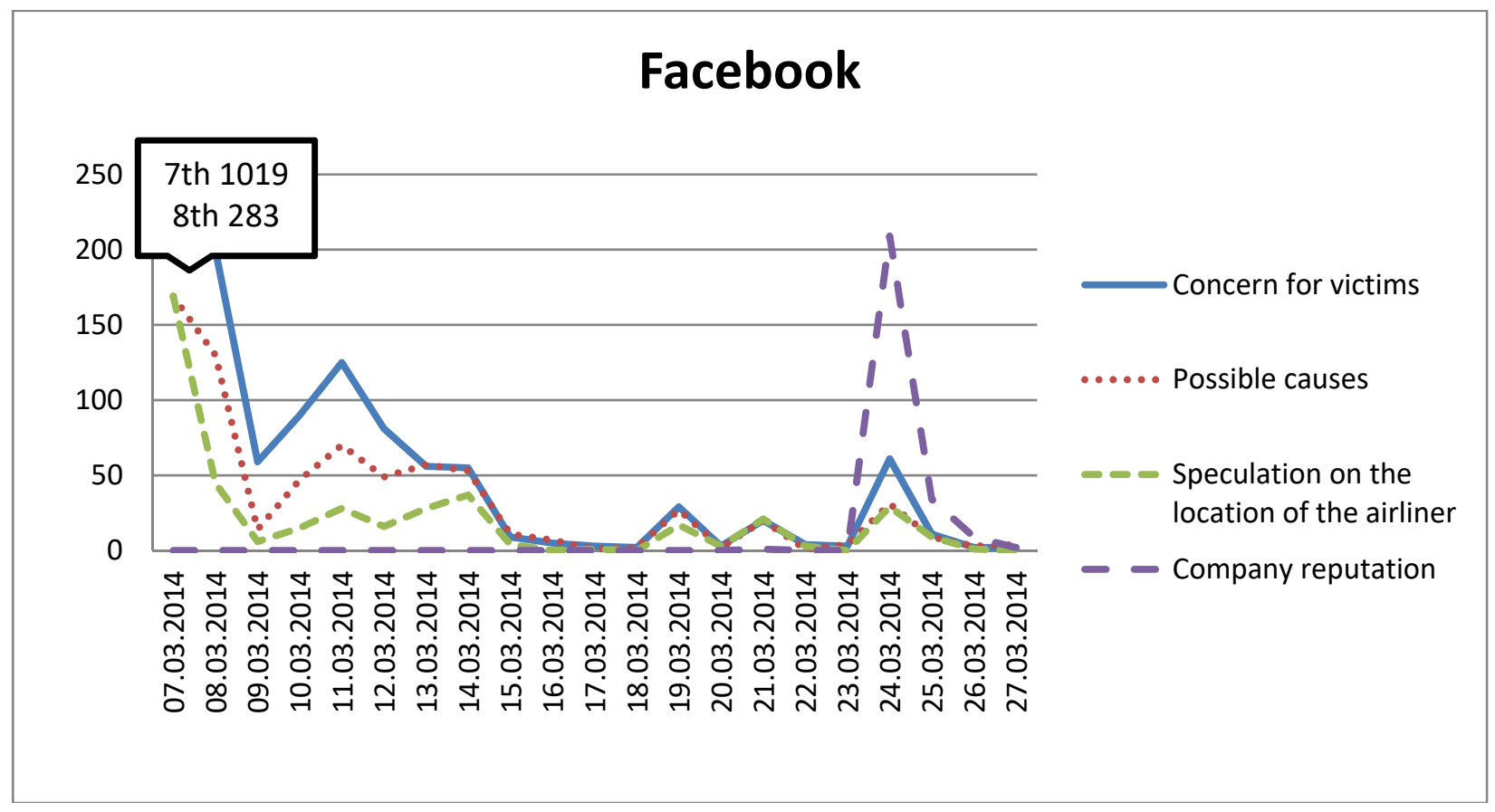

Figure 2 Frequencies of posts on Facebook chat platform of Malaysia Airlines

Figure 2 shows several peaks for certain issues: 'Concern for the victims'; 'Possible causes'; 'Speculation on the location of the airline'; and 'Company reputation'. At the beginning of the period the number of posts coded as 'Concern for victims' shows peaks of 1,019 on March 7, 2014, and 283 on March 8. On March 11, after declining over the intervening two days, the debate on Malaysia Airlines and the possibility that the Malaysian government were covering up the truth rose to top position in this theme. The proportion of posts under 'Concern for victims' continues to be generally higher than those under the other codes, until March 24, when the Malaysian prime minister makes an official announcement about the plane crash.

Discussion on possible causes was especially frequent during the period March 1314,2014 , when a shift of attention becomes visible. The number of posts coded as 'Company reputation' peaks at 209 comments on March 24, after the official announcement by the Malaysian prime minister that the plane probably crashed in the southern Indian Ocean. By the end of the period, the public's concerns have shifted significantly to the issue of 'Company reputation'. 'Concern for the victims' shows a negative correlation with 'Company reputation' (Kendall's tau_b coefficient $=-0.185$ ). Thus, later in the crisis period, people shift their attention from concern for the victims to reputation.

\section{Discussion and conclusions}

This exploratory study attempted to decompose crisis-related public debate into the various issues discussed during the lifecycle of two specific crises. The themes extracted showed the dynamics of these debates. The assumption was that during the lifecycle of the organisational crisis various issues with shorter lifecycles would 
Zhang, B., Vos, M. and Veijalainen, J. (in press, 2017), Decomposing issue patterns in crisis communication - The case of the lost airliner. Emergency Management, Vol.13.

arise. In line with this assumption, the results demonstrated that the social media discourse during the crisis consisted of a number of different issues that formed a pattern, visualized as a frequency graph.

One clear result was that compassion peaked high during the early stages of the crisis, while reputation issues emerged later on. While this may have been expected, it was now clearly shown in the data, confirming the notion that during an organisational crisis the focus of public debate will shift rather than remain fixed on a single issue. The apologia theory supports decision making on the main issue related to corporate responsibility, but neglects other issues that may need to be considered, e.g. to limit possible damage and respond to stakeholder needs.

In the case investigated, the lifecycles of the different issues were not shorter than the period measured. We suggest that in future research a longer measurement period is used as this would further clarify the lifecycles of the issues that arise during an organisational crisis. The present study period was nevertheless long enough to enable different peaks to be identified for the different issues. As the peaks showed at different points in time, these results indicate that decomposing issue patterns could help in the prioritization and timing of topics for communication initiatives. Separating the often chaotic stream of online posts into various clusters of issues and keeping track of developments over time provides a basis for strategy making.

Decomposing and analysing issue patterns during crises can be further supported by research. In this way, insights from issues management can be used, not only in the pre-crisis phase as suggested in the literature, but also during crises to facilitate strategy making in the case of longer complex crises. Moreover, various strategies may be combined as different strategies may be needed for each issue. We suggest the use of apologia and compassion strategies to deal with possible shortcomings of the organisation, warning strategies to inform publics about new risks that occur during the crisis, educative strategies to assist stakeholders in dealing with the specific challenges they face, and facilitation strategies to enable sharing of information and collaborative solutions.

If authorities and response organisations want to counteract false rumours, or confirm information, they need to occupy a built-in position of trust in the communication network (White et al., 2009), and their sources need to be easily located, e.g. by using a multi-channel approach. Organisations need to incorporate social media interaction in their communication strategies, as fostering interaction in 'normal' situations also potentially enhances relationships with stakeholders during crises (Liu and Kim, 2011). Establishing connections requires active participation in social media and enhanced interaction with users, as social media platforms can be seen as competitive issue arenas, in which multiple actors seek to gain attention for views on issues of importance to them (Luoma-aho and Vos, 2010). Social media attention to an issue is a result of messages being posted, forwarded, retweeted or 'liked'; only then will an issue gain 'momentum' in the online environment.

Nowadays communication practitioners are aware that monitoring the growth of issues is important in clarifying the information needs of stakeholders and understanding issues from their points of views during a crisis. However, during a crisis, the results of social media monitoring often present a complex and sometimes even chaotic picture for communication practitioners, making it difficult for them to maintain an overview of what is changing in public perceptions over time. Viewing a 
Zhang, B., Vos, M. and Veijalainen (in press, 2017), Decomposing issue patterns in crisis communication - The case of the lost airliner. Emergency Management, Vol. 13.

crisis as a series of more or less connected issues might help understand the discourse that evolves along with the crisis and the related changes in public concerns. Therefore, when interpreting the results of monitoring social media, it might be helpful to focus on decomposing crisis discourse into issue patterns. Similarly, researchers can investigate whether during a crisis a certain order or build-up of issues occurs that may further clarify the rapidly changing social media content. Together, the issues that arise exhibit a pattern that reflects the development of the crisis discourse over the lifecycle of the crisis.

This exploratory study focused on capturing the pattern of crisis-related issues as they evolved during the lifecycle of two different crises, to clarify the dynamics set in train by the crises, and especially how this was manifested in social media discourse. We did not relate the issues found to specific stakeholder groups; future research may show if this adds to the understanding of issue patterns. However, this study on crisis communication shows that approaching organisational crisis communication as a one-issue debate is far too simple, as a wide range of related issues may develop during a crisis. This study also points to the importance of bridging insights on communication on issues and crisis communication theory to benefit understanding of multi-issue and multi-stakeholder debate during crises.

\section{Acknowledgements}

This study has received funding by the Academy of Finland under grant agreement number 268078 "MineSocMed".

\section{References}

Anderson, I.K. (2011) 'The uses and gratifications of online care pages: a study of CaringBridge', Health Communication, Vol. 26, No. 6, pp.546-559.

Benoit, W.L. (1995) Accounts, excuses, and apologies: a theory of image restoration, State University of New York Press, Albany.

Bronstein, J. (2013) 'Like me! analyzing the 2012 presidential candidates' Facebook pages', Online Information Review, Vol. 37, No. 2, pp.173-192.

Coombs, W.T. and Holladay, S.J. (2012) 'Amazon.com's Orwellian nightmare: exploring apology in an online environment', Journal of Communication Management, Vol. 16, No. 3, pp.280-295.

Coombs, W.T. (1992) 'The failure of the task force on food assistance: a case study on the role of legitimacy in issue management', Journal of Public Relations Research, Vol. 4, No. 2, pp.101-122.

Coombs, W.T. (2001) 'Teaching the crisis management/communication course', Public Relations Review, Vol. 27, No. 1, pp.89-101. 
Zhang, B., Vos, M. and Veijalainen, J. (in press, 2017), Decomposing issue patterns in crisis communication - The case of the lost airliner. Emergency Management, Vol.13.

Coombs, W.T. (2002) 'Assessing online issue threats: issue contagions and their effect on issue prioritisation', Journal of Public Affairs, Vol. 2, No. 4, pp.215229.

Coombs, W.T. (2007) 'Protecting organisational reputations during a crisis: the development and application of Situational Crisis Communication Theory', Corporate Reputation Review, Vol. 10, pp.163-176.

Cotton, A.J., Veil, S. R. and Lannarino, N.T. (2015) 'Contaminated communication: TEPCO and organisational renewal at the Fukushima Daiichi nuclear power plant', Communication Studies, Vol.66, pp.27-44.

Crable, R.E. and Vibbert, S.L. (1985) 'Managing issues and influencing public policy’, Public Relations Review, Vol. 11, No. 2, pp.3-16.

Downs, A. (1972) 'Up and down with ecology - issue-attention cycle', Public Interest, Vol. 28, pp.38-50.

Falkheimer, J. and Heide, M. (2010) 'On dropping the tools: from planning to improvisation', in Coombs, T. and Holladay, S. (Eds.), The Handbook of Crisis Communication, Blackwell Publishing, Chichester, pp.511-526.

Frandsen, F. and Johansen, W. (2010), 'Corporate crisis communication across cultures', in Bublit, W., Jucker, A.H., and Schneider, K.P. (Eds.), Pragmatics across languages and cultures, Handbooks of pragmatics 7, De Gruyter, Berlin, pp.543-570.

Frank, B. and Schvaneveldt, S.J. (2014) 'Self-preservation vs. collective resilience as consumer responses to national disasters: A study on radioactive product contamination', Journal of Contingencies and Crisis Management, Vol. 22, No. 4, pp.197-208.

Gonzalez-Herrero, A. and Smith, S. (2008) 'Crisis communications management on the web: how internet-based technologies are changing the way public relations professionals handle business crises', Journal of Contingencies and Crisis Management, Vol. 16, No. 3, pp.143-153.

Goudarzi, S., Dadgarnejad, F. and Babaee, H. (2015) 'Viewing the future of nuclear power plants following the 2011 disaster in Fukushima nuclear power plant', Open Journal of Applied Sciences, Vol. 5, pp.220-225.

Heath, R.L., and O’Hair, H.D. (2009), 'The significance of crisis and risk communication' in Heath, R.L. and O'Hair, H.D. (Eds.), Handbook of risk and crisis communication, Routledge, New York, pp.5-30.

Gutteling, J.M. (2001) 'Current views on risk communication and their implications for crisis and reputation management', Document Design, Vol, 2, No. 3, pp.236-246.Hallahan, K. (2001) 'The dynamics of issues activation and response: an issues processes model', Journal of Public Relations Research, Vol. 13, No. 1, pp.27-59.

Heath, R.L. (1998) 'New communication technologies: an issues management point of view', Public Relations Review, Vol. 24, No. 3, pp. 273-288. 
Zhang, B., Vos, M. and Veijalainen (in press, 2017), Decomposing issue patterns in crisis communication

Heath, R.L. and Nelson, R.A. (1986), Issues management: Corporate public policymaking in an information society. Newbury Park, Sage Publications.

Heath, R.L. and Palenchar, M.J. (2009) Strategic issues management: Organisations and public policy challenges, Los Angeles, Sage Publications.

Heath, R.L. (2002) 'Issues management: its past, present and future', Journal of Public Affairs, Vol. 2, No.4, pp.209-214.

Hiltz, S.R., Diaz, P., and Mark, G. (2011) 'Introduction: social media and collaborative systems for crisis management', ACM Transactions on Computer-Human Interaction, Vol. 18, No. 4, pp.1-6.

Hughes, A.L. and Palen, L. (2009) 'Twitter adoption and use in mass convergence and emergency events', International Journal of Emergency Management, Vol. 6, No. 3/4, pp.248-260.

Hyvärinen, J., Laajalahti, A. and Vos, M. (2015) 'Enhancing citizen response to crises through communication: investigating expert views', International Journal of Emergency Management, Vol. 11, No. 4, pp.302-319.

Ionescu, T.B. (2012) 'Communicating in Germany about the Fukushima accident: how direct encounter beat media representations', Environmental Communication-a Journal of Nature and Culture, Vol. 6, No. 2, pp.260-267.

Jaques, T. (2009) 'Issue and crisis management: quicksand in the definitional landscape', Public Relations Review, Vol. 35, No. 3, pp.280-286.

Jung, J. (2012) 'Social media use and goals after the great east Japan earthquake', First Monday, Vol. 17, No. 8, pp.1-5.

Kuttschreuter, M. and Gutteling, J.M. (2009) 'Media disaster coverage over time: methodological issues and results', in Martorell, S., Guedes Soares, C., Barnett, J. (Eds.), Safety, Reliability and Risk Analysis: Theory, Methods and Applications, Taylor \& Francis, London, pp.1317-1323.

Li, J., Vishwanath, A. and Rao, H.R. (2014) 'Retweeting the Fukushima nuclear radiation disaster', Communications of the Acm, Vol. 57, No. 1, pp.78-85.

Liu, B.F. and S. Kim (2011) 'How organisations framed the 2009 H1N1 pandemic via social and traditional media: Implications for US health communicators', Public Relations Review, Vol. 37, No. 3, pp.233-244.

Luoma-aho, V. and Vos, M. (2010) 'Towards a more dynamic stakeholder model: acknowledging multiple issue arenas', Corporate Communications: An International Journal, Vol. 15, No. 3, pp.315-331.

Macnamara, J. (2016), 'Organizational Listening - The Missing Essential in Public Communication'. New York, Peter Lang.

Ng, K.H. and Lean, M.L. (2012) 'The Fukushima nuclear crisis reemphasizes the need for improved risk communication and better use of social media', Health Physics, Vol. 103, No. 3, pp.307-310. 
Zhang, B., Vos, M. and Veijalainen, J. (in press, 2017), Decomposing issue patterns in crisis communication - The case of the lost airliner. Emergency Management, Vol.13.

Nijkrake, J., Gosselt, J.F. and Gutteling, J.M. (2015) 'Competing frames and tone in corporate communication versus media coverage during a crisis', Public Relations Review, Vol. 41, No. 1, pp.80-88. Palttala, P. and Vos, M. (2012) 'Quality indicators for crisis communication to support emergency management by public authorities', Journal of Contingencies and Crisis Management, Vol. 20, No. 1, pp.39-51.

Pang, A., Hassan, N.B.B.A., and Chong, A.C.Y. (2014) 'Negotiating crisis in the social media environment.', Corporate Communications: An International Journal, Vol. 19, No. 1, pp.96-118.

Pierpoint, L. (2011) 'Fukushima, Facebook and feeds: informing the public in a digital era', Electricity Journal, Vol. 24, No. 6, pp.53-58.

Regester, M. and J. Larkin (2008) Risk issues and crisis management in public relations: a casebook of best practice, London, Kogan Page.

Reynolds, B. and Seeger, M. (2005) 'Crisis and emergency risk communication as an integrative model', Journal of Health Communication, Vol. 10, pp.43-55.

Robertson, A.G. and Pengilley, A. (2012) 'Fukushima nuclear incident: the challenges of risk communication', Asia-Pacific Journal of Public Health, Vol. 24, No. 4, pp.689-696.

Rogers, E. (1995) Diffusion of innovations, New York, Free Press.

Rogers, M., Chapman, C. and Giotsas, V. (2012) 'Measuring the diffusion of marketing messages across a social network', Journal of Direct, Data and Digital Marketing Practice, Vol. 14, No. 2, pp.97-130.

Romenti, S. and Valentini, C. (2010) 'Alitalia's crisis in the media - a situational analysis', Corporate Communication: An International Journal, Vol.15, No.4, pp.380-396.

Semenov, A. and Veijalainen, J. (2013) 'A modelling framework for social media monitoring', International Journal of Web Engineering and Technology, Vol. 8, No. 3, pp.217-249.

Stephens, K.K., Malone, P.C., and Bailey, C.M. (2005) 'Communicating with stakeholders during crisis’, Journal of Business Communication, Vol. 42, pp.390-419.

Stieglitz, S. and Dang-Xuan, L. (2013) 'Emotions and information diffusion in social media-sentiment of microblogs and sharing behaviour', Journal of Management Information Systems, Vol. 29, No. 4, pp.217-248.

Tam, D. (2012) 'Twitter gives some developers literal stamp of approval', http://news.cnet.com/8301-1023_3-57503077-93/twitter-gives-somedevelopers-literal-stamp-of-approval/ (Accessed 27 February 2015).

Terdiman, D. (2014) 'CNN, Twitter release tool to journalists find news faster', http://news.cnet.com/8301-1023_3-57618007-93/cnn-twitter-release-tool-tohelp-journalists-find-news-faster/ (Accessed 27 February 2015). 
Zhang, B., Vos, M. and Veijalainen (in press, 2017), Decomposing issue patterns in crisis communication

Ulmer, R., Sellnow, T. and Seeger, M. (2007) Effective crisis communication. Moving from crisis to opportunity, Sage Publications, Thousand Oaks.

Utz, S., Schultz, F. and Glocka, S. (2013) 'Crisis communication online: how medium, crisis type and emotions affected public reactions in the Fukushima Daiichi nuclear disaster', Public Relations Review, Vol. 39, No. 1, pp.40-46.

Veil, B., Reynolds, B., Sellnow, T., and Seeger, M. (2008) 'CERC as a theoretical framework for research and practice', Health Promotion Practice Vol. 9, No. 4, pp.26S-34S.

Vos, M. and Schoemaker, H. (2011) Integrated communication: concern, internal and marketing communication, Eleven International Publishing, The Hague.

Wang, H. (2012) 'Six P's of youth social media from a young consumer's perspective', Young Consumers, Vol. 13, No. 3, pp.303-317.

Wang, X. Y., Kato, H. and Shibasaki, R. (2013) 'Risk perception and communication in international maritime shipping in Japan after the Fukushima Daiichi nuclear power plant disaster', Transportation Research Record, Vol. 2330, pp.87-94.

White, C., Plotnick, L., Kushma, J., Hiltz, S.R. and Turoff, M. (2009) 'An online social network for emergency management', International Journal of Emergency Management, Vol. 6, No. 3/4, pp.369-382.

Wright, D.K. and Hinson, M. (2009) 'An updated look at the impact of social media on public relations practice'. Public Relations Journal, Vol. 3, No. 2, pp. 1-17.

Wybo, J.L., Soulié, F.F., Gouttas, C., Freyssinet, E. and Lions, P. (2015) 'Impact of social media in security and crisis management: a review', International Journal of Emergency Management, Vol.11, No.2, pp.105-128.

Zhang, B. and Vos, M. (2014) 'Social media monitoring: methods, benefits and difficulties for international companies', Corporate Communications, an International Journal, Vol. 19, No. 4, pp.371-383.

Zhang, B. and Vos, M. (2015) 'How and why some issues spread fast in social media', Online Journal of Communication and Media Technologies, Vol. 5, No. 1, pp.371-383.

Zhao, J., Wu, J. and Xu, K. (2010) 'Weak ties: subtle role of information diffusion in online social networks', Physical Review E, Statistical, nonlinear, and soft matter physics, Vol. 82, No. 1. 